\title{
0 uso do mobile banking: uma aplicação do Modelo de Prontidão a Tecnologia (TRI) via Mínimos Quadrados Parciais (PLS)
}

\author{
Sérgio Ricardo Gaspar \\ Doutorando em Administração. Centro Universitário da Fundação Educacional Inaciana "Padre \\ Sabóia de Medeiros" (FEI) - Brasil. sergio.gaspar@usp.br \\ Renato de Moraes Ferreira Mestre em Administração. Universidade Municipal de São Caetano do Sul (USCS) - Brasil. \\ renato.fatec@gmail.com \\ Leandro Prearo Doutor em Administração. Universidade Municipal de São Caetano do Sul (USCS) - brasil. \\ leandro.prearo@uscs.edu.br
}

RESUMO

Os avanços tecnológicos aos quais os consumidores são expostos são de suma importância para as organizações, assim como o acompanhamento da aprendizagem e aceitação do uso das tecnologias, e oferecimento de produtos e serviços. Este estudo definiu como objetivo principal avaliar o uso de serviços bancários associados ao mobile banking, através da aplicação do instrumento de medida utilizado por Parasuraman e Colby (2002) denominado TRI. Utilizou-se uma amostra de 261 clientes bancários, sendo que validados 219 questionários. A pesquisa aqui proposta pode ser classificada, em função de sua natureza como básica, quanto à abordagem do problema como quantitativa, e do ponto de vista de seus objetivos, como exploratória e descritiva. Houve pesquisa de campo, com posterior tabulação dos dados coletados e análise dos resultados a partir de procedimentos estatísticos relevantes aos objetivos do estudo.

Palavras-Chave: Mobile banking. Prontidão Tecnológica. TRI.

\section{The use of mobile banking: an application of Technology Readiness Model (TRI) in Partial Least Squares (PLS)}

\begin{abstract}
Technological advances to which consumers are exposed is very important for organizations, and the monitoring of learning and acceptance of the use of technology, and offering products and services. This study defined as main objective to evaluate the use of banking services associated with mobile banking through the application of the measuring instrument used by Parasuraman and Colby (2002) called TRl, we used a sample of 261 bank customers, being validated 219 questionnaires. The proposed research can be classified as quantitative, and from the point of view of its objectives, such as exploratory and descriptive. There was field research with subsequent tabulation of the data collected and analysis of results from statistical procedures Partial Least Squares (PLS). The results show that it was possible to verify that the construct was uncertainty with a higher coefficient in relation to the variable declared use. Therefore, it is concluded that the higher the lower uncertainty factor is the use of services, for future research suggested that replication of this study with a larger sample in other financial institutions.
\end{abstract}

Keywords: Mobile banking. Technology Readiness. Technology Readiness Index. 


\section{INTRODUÇÃO}

Acompanhar os avanços tecnológicos aos quais os consumidores são expostos é de suma importância para as organizações, assim como o acompanhamento da aprendizagem e aceitação do uso das tecnologias, o oferecimento de produtos e serviços de fácil manuseio e que satisfaçam os consumidores.

Faz-se necessário para as organizações, em especial as que tomam a tecnologia como um diferencial de mercado, pesquisar e acompanhar a evolução da prontidão para tecnologia ${ }^{1}$ de seus usuários. A relevância é de tal ordem que segundo Parasuraman e Colby (2002), a compreensão equivocada das atitudes e anseios de segmentos de consumidores frente às tecnologias, afeta o entendimento de possíveis demandas de mercado, qualidade ofertada de serviço, e, por conseguinte a estruturação de estratégicas organizacionais.

Souza e Luce (2003), Meuter, Ostrom, Roudtree et al. (2000), Parasuraman (2000) e, Rosen, Sears e Weil (1987) expõem que mesmo com melhorias propiciadas pela tecnologia relativas à conveniência e eficiência na oferta de serviços e produtos, a frustração gerada em clientes bancários parte de experiências negativas acumuladas por estes no uso de produtos tecnológicos.

Definiu-se como objetivo principal deste artigo avaliar o uso de serviços bancários associados ao mobile banking a uma amostra de usuários do sistema bancário brasileiro, através da aplicação de questionário. Cujos resultados serão avaliados por meio de uma escala de mensuração TRI, instrumento este criado por Parasurama e Colby (2002) ajustada ao caso brasileiro por Souza e Luce (2005), e que subsidia a análise de prontidão de usuários de serviços bancários baseados em mobile banking a partir de condutores e inibidores mentais relacionados ao otimismo, inovatividade, desconforto e insegurança de usuários de serviços bancários.

O presente artigo é o desdobramento da apresentação feita no evento intitulado XIX Seminários em Administração apresentado em 2016 e, se propõe a responder a seguinte indagação: Qual o nível de prontidão para o uso da tecnologia de mobile banking por clientes bancários?

A estrutura desta pesquisa em um primeiro momento é introduzida pelo referencial teórico sobre adoção de tecnologia, logo após discorre-se sobre a Technology Readiness Index (TRI), a seguir apresentase a conceituação de serviços móveis e mobile banking. Expõe-se também a metodologia aplicada em detalhes, faz-se a análise estatística dos dados e, por fim, chega-se às considerações finais.

\subsection{Objetivo da pesquisa}

Esta pesquisa tem por objetivo principal identificar a percepção de clientes bancários sobre o uso do mobile banking, através da aplicação do instrumento de medida utilizado por Parasuraman e Colby (2002) denominado TRI, e validado para o contexto brasileiro por Souza e Luce (2005), a fim de acompanhar sua evolução e aplicabilidade.

Um segundo objetivo dessa pesquisa é a identificação do perfil, da influência e do nível de prontidão para uso de tecnologia, assim como a mensuração da inovatividade, do nível de otimismo, de insegurança, e de desconforto de usuários de mobile banking de uma instituição financeira.

\section{REFERENCIAL TEÓRICO}

O referencial teórico deste estudo está dividido em três segmentos, inicialmente apresentam-se as explicações referentes adoção tecnológica, o segundo ponto é o associado à escala TRI de Parasuraman e Colby (2002) e a conceituação de mobile banking.

\footnotetext{
1 A prontidão para tecnologia - Technology Readiness (TR) diz respeito à propensão dos indivíduos para adotar novas tecnologias (PARASURAMAN, 2000 apud SOUZA, 2002, p. 30). Segundo Parasuraman e Colby (2001), as dimensões condutoras e inibidoras da prontidão para tecnologia atuam independentemente, de forma que uma pessoa pode possuir qualquer combinação de motivações ou inibições. Nesse sentido, um indivíduo pode ser inovador em tecnologia, propenso à experimentação, mas cético a respeito do valor da tecnologia. Em outras palavras, pode acreditar na tecnologia, mas, ao mesmo tempo, temê-la. (SOUZA, 2002, p.32)
} 


\subsection{Adoção de tecnologia}

Para Parasuraman e Colby (2002) a resistência à adoção de produtos ou serviços baseados em tecnologia, é acentuada em casos em que o consumidor é considerado inexperiente, pois o mesmo nota um risco maior na adoção da inovação. Por sua vez, Saaksjarvi (2003) sugere que a adoção da inovação pode ser restringida caso não haja uma conexão entre o estilo de vida do consumidor, seus valores e suas experiências passadas com a inovação tecnológica proposta (PONTAROLO, 2014, p. 58). Seguindo o entendimento de Saaksjarvi (2003), o consumidor apenas dispensará esforço para o aprendizado de novas tecnologias, se e somente se estas provarem ser compatíveis e complementares ao conhecimento prévio que este já detenha.

Robertson (1971) em seus estudos, considera que os adotantes de inovações tecnológicas possuem heterogeneidade significativa, e que esta influencia a velocidade com que os consumidores adotam tecnologias. Sobretudo, variando a velocidade de adoção tecnológica pelo tipo e pela continuidade a qual se expõe o consumidor. A relevância da velocidade de adoção de tecnologias por clientes é igualmente abortada por Midgley e Dowling (1978), e de acordo com estes autores a velocidade de adoção funcionaria como critério para a distinção entre adotantes iniciais e adotantes tardios de novas tecnologias.

Mas, para que se possa minimizar o tempo ou mesmo vencer barreiras de não adoção de tecnologias deve-se desenvolver tecnologias que se pautem pelo uso do consumidor, como indicado por Saaksjarvi (2003). O que se coaduna ao defendido por Parasuraman e Colby (2002), quando estes referem-se ao projeto centrado em clientes que apresentem alto grau de desconforto e insegurança com a tecnologia, sendo mister o desenvolvimento de produtos e serviços que garantam controle do uso da inovação a este perfil de consumidor.

Conforme Parasuraman e Colby (2002) a tecnologia centrada no consumidor deve ser:

- Eficiente - minimizar sequências ou repetições de ações para que se obtenha a resposta esperada pelo uso do serviço ou produto ofertado;

- Intuitiva - seja de fácil manuseio por parte do cliente, evitando-se recorrer a explicações ou apoio de terceiros;

- Tranquilizadora - sinaliza-se ao consumidor que o funcionamento manter-se-á como o esperado e em caso contrário a falha será identificada facilmente pelo cliente;

- Compatível - adaptar-se aos produtos e serviços que o consumidor já detenha.

A adoção e os determinantes do grau de prontidão dos clientes a inovações tecnológicas são aspectos incluídos no constructo prontidão para tecnologia e que se relacionam ao perfil psicológico e comportamental dos consumidores. Dado que as características dos tipos de adotantes de tecnologia é multifacetada e complexa, Rogers (1995) atribuiu graus de inovatividade ao consumidor e desta forma apontou estes aspectos como diferenciadores entre categorias de consumidores.

Por sua vez aspectos emocionais como o afeto e a cognição dos clientes, ainda que distintos entre si são inter-relacionados no entendimento de Perter e Olson (1994), afetando sentimentos e crenças; por conseguinte, o processo de decisão de adoção de novas tecnologias aos consumidores. Um terceiro aspecto de acordo com Engel, Blackwell e Miniard (2011) relaciona a atitude do consumidor às intenções comportamentais (PONTAROLO, 2014). Visto que os aspectos emocionais e cognição se inter-relacionam, e há coexistência de emoções positivas e negativas em relação às novas tecnologias segundo Mick e Fournier (1998), originam-se deste contexto os paradoxos tecnológicos.

Dentre os fatores cognitivos que afetam a intenção de adoção de uma tecnologia está a compreensão pelo cliente de que a adoção poderá gerar benefícios e conveniência à realização de suas tarefas. Assim, quando o consumidor analisa e identifica vantagens em relação às tecnologias anteriormente utilizadas, fará com que sua intenção de adoção à tecnologia aumente de acordo com Rogers (2003). Da mesma forma, que a facilidade de uso se torna mais significante por representar uma maior utilidade ao cliente (DAVIS et al., 1989).

Para Pontarolo (2014) é possível identificar características sobre a prontidão à tecnologia que passam pelo caráter multifacetado do construto, onde sentimentos e crenças afetam o consumidor no momento da adoção da tecnologia e modificam o grau de satisfação. Portanto, a associação de fatores cognitivos e emocionais potencializam atitudes de adoção de inovações tecnológicas como indicado por Rogers (2003), a 
velocidade da adoção como explanado por Midgley e Dowling (1978) e o entendimento de Saaksjarvi (2003) sobre o esforço de adoção pelo consumidor.

Como exemplo de aplicação dos conceitos até aqui expostos sustenta-se que a adoção de tecnologias aclara o recente crescimento do uso de smartphones com acesso à internet e o uso de aplicativos com variadas funções, incluindo-se os da área de transações bancárias ou mais comumente definido mobile banking.

\subsection{Technology Readiness Index}

A Technology Readiness Index (TRI) é uma escala de mensuração elaborada a partir de um programa de pesquisa e baseadas em um constructo idealizado por A. Parasuraman e C. Colby. Segundo Parasuraman e Colby (2002) o TRI é um instrumento desenvolvido para ser aplicado aos consumidores do mercado norteamericano, onde este foi otimizado com evidências de dezenas de grupos de discussão e diversos setores da economia, gerando um instrumento consistente e confiável.

Parasuraman e Colby (2002), construíram a escala TRI a partir de quatro fatores com 36 indicadores da prontidão para tecnologia, e possuidora de indícios da qualidade do instrumento por sua capacidade de predizer comportamentos, fazendo-se forçoso em contextos distintos da origem o teste do TRI.

Pontarolo $(2014$, p. 50) indica dois casos em que o TRI foi colocado à prova. O primeiro é no caso do Brasil, onde as pesquisas de Souza e Luce $(2003,2005)$ validaram o instrumento por meio de análise fatorial confirmatória e no segundo caso Nikos Tsikriktsis da London Business School (2004) propôs a replicação da escala TRI no contexto britânico para a classificação dos tipos de consumidores estabelecido por Parasuraman e Colby (2002).

Sendo que os resultados obtidos nos dois casos acima, indicaram que o TRI pode contribuir para a diferenciação entre usuários e não usuários de produtos tecnológicos, e para a prognóstico de adoção destes produtos (PIRES, COSTA FILHO, 2008, p. 431).

Em concordância com a conceituação de Parasuraman e Colby (2002), a prontidão para tecnologia é composta por quatro dimensões:

1) Otimismo: os autores definem esta face da adoção de tecnologia como positiva, de tal modo que se faz crer que esta proporcionaria as pessoas maior controle, flexibilidade e eficiência no seu cotidiano;

2) Inovatividade (ou caráter inovador): relaciona a liderança de opinião e inovação ao consumo de tecnologia, estimulando o consumidor a experimentar e adquirir produtos inovadores como meio de manutenção de status;

3) Desconforto: inibe da TR e a relaciona à falta de controle percebido sobre a tecnologia, propiciando o sentimento subjugação por esta. Esta face representa a extensão da paranoia das pessoas associada a produtos e serviços baseados em tecnologia, crendo que estes tendem a ser socialmente excludentes;

4) Insegurança: A insegurança vai ao encontro do desconforto, destacando-se que o fator que a afeta é desconfiança da tecnologia e não inaptidão do consumidor em empregá-la. Sendo esta dimensão gerada por aspectos intrínsecos à tecnologia e geralmente pela ausência do contato humano, principalmente nas transações on line. 
Figura 1- Aspectos associados à disposição para tecnologia

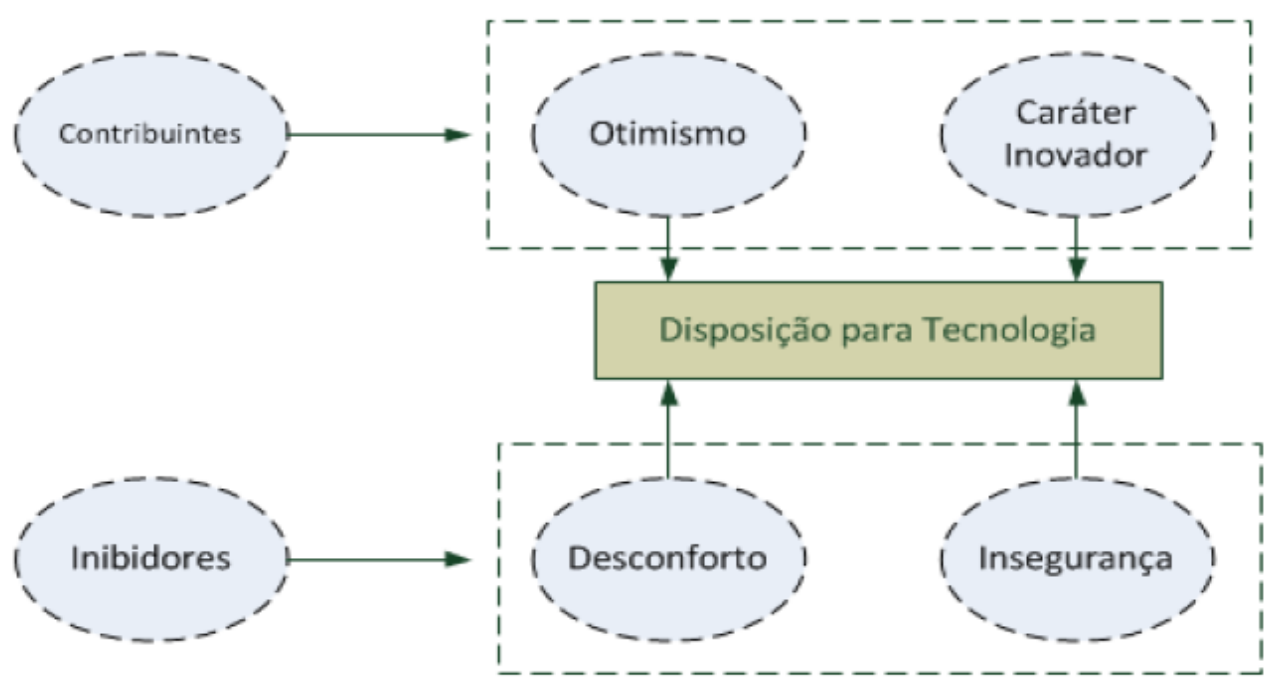

Fonte: Adaptado de Parasuraman e Colby (2002).

As dimensões otimismo e inovatividade indicam fatores que promovem as pessoas a adotarem novas tecnologias, ou seja, são dimensões condutoras da prontidão para tecnologia. Todavia, as dimensões desconforto e insegurança pela leitura de Parasuraman e Colby (2002) são inibidores, isto é, são fatores que retardam ou impedem a adoção de novas tecnologia, como esquematicamente exposto na figura 1.

De acordo com Souza e Luce (2005) a combinação das quatro dimensões gera a prontidão geral para tecnologia do consumidor, ou seja, não apenas a capacidade técnica ou sua celeridade no manuseio de equipamentos tecnológicos é o que lhe faz adotar dada tecnologia. Isto denota, que elementos relacionados ao otimismo, desconforto e insegurança, são tão ou mais relevantes que somente na dimensão inovatividade.

\subsection{Serviços móveis}

A Federação Brasileira dos Bancos (FEBRABAN) por meio de "Pesquisa FEBRABAN de Tecnologia Bancária 2014", aponta que as estratégias comerciais das instituições financeiras devem levar em consideração na garantia da viabilidade do modelo de negócio com a ampliação da oferta de canais de transação financeira e de comunicação eletrônicos, facilitação do uso dos produtos e serviços contratados por seus clientes, para que desta maneira aumente-se o nível confiança deste consumidor (FEBRABAN, 2016).

Segundo Pires e Costa Filho $(2008$, p. 434) as organizações bancárias detêm experiência de longa data na introdução e disseminação de novas tecnologias para a interação com clientes como por exemplo centrais de teleatendimento e on line banking. O que de acordo com os autores, esta é uma área em que muitas instituições financeiras buscam estratégias de minimização de custos, majoração de receitas e retenção de cliente.

Kalakota e Robinson (2002) a oferta de serviços bancários móveis por bancos voltam-se a clientes ocupados e que procuram conveniência. Ligado a isso, o uso crescente de smartphones habilitados ou cadastrados aliados ao acesso facilitado a aplicativos financeiros a clientes bancários, permite a realização de operações bancárias diversas. Tais como o acesso remoto a saldos, transferências e pagamentos, dentre outros serviços. Então, as facilidades agora disponíveis por estes aplicativos ajudam a entender a disseminação do uso deste tipo de serviço/produto junto ao consumidor bancário, como é identificado em estudo da FEBRABAN no ano de 2014. 


\subsubsection{Serviço de mobile banking}

Para que se aprofunde a questão da mobilidade, faz-se necessário defini-la, para tanto tomaremos o conceito de Kalakota e Robinson (2002) que a expõem como "acesso totalmente portátil em tempo real aos mesmos recursos e ferramentas de informação que, até recentemente, somente eram acessíveis pelo computador desktop, na mesa de trabalho(...)".

Conforme Kalakota e Robinson (2002) a mobilidade proporcionada pelos telefones celulares aliada ao crescimento de utilização pelo consumidor de meios de pagamentos eletrônicos fez surgir o interesse em soluções para pagamentos pelo celular (MARTINS, 2003, p. 43). Por sua vez, Pousttchi e Schurig (2004) assinalam que com a disseminação do uso destes aparelhos houve um natural aumento do uso de aplicativos móveis e diminuiu-se o uso de bancos e caixas eletrônicos.

Visto que o mobile banking facilita aos clientes bancários transações financeiras, consultas diversas às contas correntes, em conjunto com a comodidade, eficiência e acesso ao serviço 24 horas por dia. Todavia, a mudança tecnológica proporcionada pelo mobile banking para o cliente não necessariamente gera apenas aspectos positivos, podendo ser inclusive ser paradoxal como descrito por Mick e Fournier (1998), destacandose características atitudinais na diferenciação entre usuários e não usuários de produtos e serviços financeiros.

Jeunon (2005) indica que há dois enfoques de modelo de atendimento, o automatizado ou o intermediado por funcionário da organização, e em decorrência da possibilidade de escolha do modelo de atendimento instala-se um processo de tomada de decisão por parte do cliente. Sendo que para Rita, Viana Filho e Paula (2008) e Engel, Blackwell e Miniard (2011) o exame do comportamento do consumidor deva-se basear em fatores que exerçam influência sobre questões pessoais e socioculturais.

Rocha e Belivacqua (2011, p. 4) defendem que clientes favoráveis à tecnologia e apreciadores da conveniência em função de postura mais autônoma frente ao atendimento realizado por pessoas, dão preferência a canais eletrônicos de atendimento tais como caixas automáticos, internet banking e mais recentemente o mobile banking.

\section{METODOLOGIA}

A pesquisa aqui proposta pode ser classificada, em função de sua natureza como básica, quanto a abordagem do problema como quantitativa, e do ponto de vista de seus objetivos, como exploratória e descritiva. Houve pesquisa de campo, com posterior tabulação dos dados coletados e análise dos resultados a partir de procedimentos estatísticos relevantes aos objetivos do estudo.

O instrumento de coleta foi baseado na escala TRI, que é composta por 36 afirmações que compreende aspectos relativos às dimensões otimismo, inovatividade, desconforto e insegurança para aferir a prontidão à tecnologia do consumidor, a produtos e serviços baseados em tecnologia. $O$ instrumento aplicado limitou o universo de pesquisa a usuários de serviços bancários, tomando como base o estudo original de Parasuraman e Colby (2002), mas ajustado ao contexto brasileiro por Souza e Luce (2003).

\subsection{Coleta e validação dos questionários junto aos clientes bancários}

Foram entregues questionários baseados na ferramenta TRI, a 261 clientes bancários que aguardavam atendimento presencial em uma agência bancária localizada no distrito de São Miguel Paulista do município de São Paulo. De início os clientes demonstraram fácil compreensão do questionário e por consequência aos itens formadores da escala TRI. Sendo que poucos itens da escala sofreram ajustes cuidadosos na forma escrita, de maneira a facilitar o entendimento do entrevistado e não afetar a significação do item da escala.

De início descartou-se 42 questionários, sendo que 28 destes foram devolvidos ao entrevistador sem que qualquer das questões fossem respondidas e os 14 questionários restantes foram descartados pois o preenchimento foi feito de maneira incorreta pelos clientes entrevistados. Validou-se desta maneira, 219 
questionários, representando $83,90 \%$ do total de questionários aplicados aos clientes bancários da agência supracitada, para fins de compilação de dados e análise estatística.

O questionário aplicado aos entrevistados atribuiu graus de concordância de 1 a 10 às afirmações, sendo 1 referente a "Discordo Totalmente" e 10 indicativa a "Concordo Totalmente". A caracterização do entrevistado inseriu-se questões pertinentes às características dos respondentes, como faixa etária, grau de instrução, renda familiar e sexo.

Destaca-se que para a efetivação dessa coleta de dados para o desenvolvimento da presente pesquisa, foi possível tão somente porque a instituição bancária através de sua Diretoria de Gestão de Pessoas permitiu a abordagem de seus clientes em suas dependências no período compreendido entre 11 e 18 de março de 2016.

\subsection{Método estatístico}

O método estatístico utilizado foi de regressão Partial Least Squares (PLS). Procedimento inicialmente proposto por Herman Wold em 1966, quando este apresentou dois processos iterativos que utilizavam estimação por mínimos quadrados para modelos com múltiplos componentes e para correlação canônica (PREARO, 2013).

O PLS é uma técnica estatística de dados multivariados que analisa uma ou mais variável-resposta (X) com variáveis-independentes $(Y)$, com o uso de fatores. O PLS permite identificar fatores (combinações lineares das variáveis $\mathrm{X}$ ) que melhor modelam as variáveis-dependentes $\mathrm{Y}$. $\mathrm{E}$, admite trabalhar eficientemente com conjuntos de dados onde haja variáveis altamente correlacionadas.

Optou-se para análise dos dados coletados nesse artigo a utilização do software estatístico SMARTPLS 3.0. De acordo com Ringle, Silva e Bido (2014) como o PLS é uma possibilidade da Modelagem de Equações Estruturais (MEE) há uma simbologia que o leitor familiarizar-se-á através da figura 2:

Figura 2 - Símbolos usados para os modelos de equações estruturais

\begin{tabular}{|l|l|}
\hline & \multicolumn{1}{|c|}{ DEFINIÇÃo } \\
\hline
\end{tabular}

Fonte: Ringle, Silva e Bido (2014).

\section{ANÁLISE DOS RESULTADOS}

Esse capítulo foi dividido em duas partes. Na primeira parte é apresentado o perfil da amostra e na segunda parte a Modelagem de Equações Estruturais Baseada nos Mínimos Quadrados Parciais. 


\subsection{Perfil da amostra}

Nos 219 questionários validados chamam a atenção as seguintes características dos entrevistados:

- Predominância do sexo feminino: $56,7 \%$ de mulheres contra $42,5 \%$ homens;

- A idade média dos entrevistados foi de 35 anos, com mediana de 33 anos e desvio-padrão de 12 anos;

- Predominância de ensino médio completo (51,9\%), seguido de superior completo (19,9\%);

Com relação à faixa de renda, mas de $60 \%$ da amostra apresenta renda familiar entre $\mathrm{R} \$ 880$ e $\mathrm{R} \$$ 3.520. Destaque-se que $17 \%$ dos entrevistados afirmaram possuir renda familiar de até um salário-mínimo $(R \$$ $880,00)$

Referente às instituições bancárias, $89 \%$ dos entrevistados afirmaram ser correntistas de algum banco (38\% de mais de um banco), com destaque para o Banco do Brasil (43\% dos entrevistados), Itaú (30\% dos entrevistados), CEF ( $22 \%$ dos entrevistados), Santander (12\% dos entrevistados).

Ainda com relação aos serviços bancários, cabe registrar que 45,6\% da amostra informou utilizar o mobile banking de seu banco para realizar algum tipo de transação.

\subsection{O modelo TRI}

A Tabela 1 apresenta as estatísticas descritivas de cada uma das variáveis incluídas no modelo como variáveis independentes e exógenas. Chama a atenção de entre as 36 assertivas do modelo, apenas uma apresentou nota média inferior a 5 - às vezes, você pensa que os sistemas tecnológicos não foram projetados para o uso de "pessoas comuns". Ainda, de forma geral, registre-se que oito notas foram superiores à 8 , com destaque para o constructo otimismo, com 5 dessas notas mais altas, sendo distribuídas entre 1 e 10.

Tabela 1 - Estatísticas descritivas das variáveis de TR

\begin{tabular}{|c|c|c|c|}
\hline Assertiva & Média & Mediana & $\begin{array}{l}\text { Desvio- } \\
\text { Padrão }\end{array}$ \\
\hline \multicolumn{4}{|l|}{ Constructo Otimismo } \\
\hline A tecnologia faz com que você fique mais eficiente nas suas atividades profissionais. & 7,63 & 8,00 & 2,9 \\
\hline Produtos e serviços bancários que utilizam tecnologias atuais são mais convenientes para usar. & 7,31 & 8,00 & 2,7 \\
\hline Aprender sobre a tecnologia pode ser tão recompensador quanto a própria tecnologia. & 7,31 & 8,00 & 2,7 \\
\hline A tecnologia lhe oferece maior liberdade de movimento. & 7,21 & 8,00 & 2,8 \\
\hline $\begin{array}{l}\text { Você gosta de aplicativos em smarthphones que permitem adequar as tarefas as suas próprias } \\
\text { necessidades. }\end{array}$ & 7,03 & 8,00 & 3,4 \\
\hline A tecnologia dá às pessoas controle sobre o dia a dia. & 6,96 & 8,00 & 2,7 \\
\hline Você prefere utilizar a mais avançada tecnologia disponível. & 6,91 & 8,00 & 3,5 \\
\hline Você acha que as novas tecnologias são mentalmente estimulantes. & 6,73 & 7,00 & 2,9 \\
\hline $\begin{array}{l}\text { Você gosta da ideia de fazer negócios via aplicativo do seu banco no smarthphone porque eles não } \\
\text { estão limitados aos horários comerciais. }\end{array}$ & 6,43 & 8,00 & 3,6 \\
\hline Você se sente seguro de que as máquinas seguirão as suas instruções. & 6,21 & 7,00 & 3,0 \\
\hline Constructo Inovatividade & Média & Mediana & $\begin{array}{l}\text { Desvio- } \\
\text { Padrão }\end{array}$ \\
\hline Você gosta do desafio de entender equipamentos de alta tecnologia. & 6,74 & 7,00 & 3,0 \\
\hline $\begin{array}{l}\text { Você se mantém atualizado com os últimos desenvolvimentos tecnológicos de suas áreas de } \\
\text { interesse. }\end{array}$ & 6,47 & 7,00 & 3,1 \\
\hline Parece que seus amigos estão aprendendo sobre as mais novas tecnologias mais do que você. & 6,34 & 7,00 & 3,2 \\
\hline Você acha que tem menos problemas do que os outros em fazer a tecnologia trabalhar para você. & 6,15 & 6,00 & 2,9 \\
\hline $\begin{array}{l}\text { Você normalmente consegue assimilar novos produtos e serviços de alta tecnologia sem ajuda de } \\
\text { outras pessoas. }\end{array}$ & 6,13 & 7,00 & 3,3 \\
\hline As outras pessoas Ihe pedem conselhos sobre novas tecnologias. & 5,95 & 7,00 & 3,3 \\
\hline $\begin{array}{l}\text { Em geral, você está entre os primeiros de seu grupo de amigos a adquirir uma nova tecnologia } \\
\text { logo que ela surge. }\end{array}$ & 5,05 & 5,00 & 3,1 \\
\hline
\end{tabular}




\begin{tabular}{|c|c|c|c|}
\hline Constructo Desconforto & Média & Mediana & $\begin{array}{l}\text { Desvio- } \\
\text { Padrão }\end{array}$ \\
\hline Novas tecnologias tornam muito fácil para o governo e as empresas espionarem as pessoas & 7,27 & 8,00 & 3,1 \\
\hline $\begin{array}{l}\text { Na compra de um produto ou serviço bancário, você prefere o atendimento presencial ao } \\
\text { atendimento on line. }\end{array}$ & 6,76 & 8,00 & 3,4 \\
\hline $\begin{array}{l}\text { Deveria haver cuidados na substituição de pessoas pelas tecnologias, pois as novas tecnologias } \\
\text { podem falhar. }\end{array}$ & 6,89 & 8,00 & 3,2 \\
\hline As tecnologias parecem sempre falhar nos piores momentos possíveis & 6,73 & 7,00 & 3,3 \\
\hline $\begin{array}{l}\text { Muitas das novas tecnologias apresentam riscos à saúde ou à segurança que não são descobertos } \\
\text { até que as pessoas tenham utilizado a tecnologia. }\end{array}$ & 5,95 & 6,00 & 3,2 \\
\hline $\begin{array}{l}\text { É constrangedor quando você tem problemas com equipamentos de alta tecnologia, enquanto } \\
\text { outras pessoas estão observando. }\end{array}$ & 5,84 & 6,00 & 3,3 \\
\hline Os manuais de produtos e serviços de alta tecnologia não são escritos em linguagem comum. & 5,76 & 6,00 & 3,2 \\
\hline $\begin{array}{l}\text { Quando você tem suporte técnico de um fornecedor de alta tecnologia em produtos e serviços, } \\
\text { você às vezes sente-se como alguém tirando proveito por saber mais do que você. }\end{array}$ & 5,41 & 6,00 & 3,3 \\
\hline $\begin{array}{l}\text { Os serviços de suporte técnico (por telefone ou internet) não são úteis porque não conseguem } \\
\text { explicar as coisas em termos compreensíveis. }\end{array}$ & 5,20 & 5,00 & 3,2 \\
\hline $\begin{array}{l}\text { Às vezes, você pensa que os sistemas tecnológicos não foram projetados para o uso de pessoas } \\
\text { comuns. }\end{array}$ & 4,99 & 5,00 & 3,3 \\
\hline Constructo Insegurança & Média & Mediana & $\begin{array}{l}\text { Desvio- } \\
\text { Padrão }\end{array}$ \\
\hline O contato humano é muito importante, quando fazemos negócios com uma instituição financeira. & 7,63 & 9,00 & 3,1 \\
\hline $\begin{array}{l}\text { Quando você liga para uma instituição financeira para tratar de negócios, você prefere falar com } \\
\text { uma pessoa ao invés de falar com uma secretária eletrônica ou aplicativos financeiros. }\end{array}$ & 7,48 & 9,00 & 3,2 \\
\hline $\begin{array}{l}\text { Sempre que algo é automatizado, você deve checar cuidadosamente se o smartphone ou } \\
\text { computador não estão cometendo erros. }\end{array}$ & 6,98 & 8,00 & 3,3 \\
\hline $\begin{array}{l}\text { Quaisquer transações financeiras que você faz eletronicamente deveriam ser confirmadas } \\
\text { posteriormente por algo escrito. }\end{array}$ & 6,72 & 8,00 & 3,5 \\
\hline $\begin{array}{l}\text { Você tem receio de que as informações que você envia pela internet ou mobile banking serão vistas } \\
\text { por outras pessoas. }\end{array}$ & 6,33 & 7,00 & 3,4 \\
\hline $\begin{array}{l}\text { Você não se sente seguro em informar o número de seu cartão de crédito pelo computador ou } \\
\text { aplicativo financeiro. }\end{array}$ & 6,24 & 7,00 & 3,6 \\
\hline $\begin{array}{l}\text { Quando você fornece informações para um smartphone ou pela internet, você não pode ter certeza } \\
\text { de que ela chegou ao destinatário correto. }\end{array}$ & 6,10 & 7,00 & 3,6 \\
\hline Você não se sente seguro em realizar transações bancárias pela internet ou aplicativo financeiro. & 6,09 & 7,00 & 3,5 \\
\hline $\begin{array}{l}\text { Você não considera seguro fazer qualquer tipo de transação financeira pela internet ou aplicativo } \\
\text { financeiro. }\end{array}$ & 5,74 & 6,00 & 3,5 \\
\hline
\end{tabular}

Fonte: Editado pelos autores (2017)

$\mathrm{Na}$ análise do modelo, foram feitas várias aplicações sucessivas. De forma parcimoniosa, as variáveis com carga fatorial abaixo de 0,70 foram retiradas do modelo - conforme sugere (Hair et al., 2014), da menor para maior, até que a média dessas cargas fosse maior do que 0,50 Variância Média Extraída (AVE). Nesse sentido, as variáveis retiradas foram:

- Constructo Otimismo: questão 01 (A tecnologia permite que as pessoas tenham mais controle sobre o seu dia a dia)

- Constructo Inovatividade: questão 12 (Parece que seus amigos estrão aprendendo sobre as mais novas tecnologias mais do que você)

- Constructo Desconforto: questões 18 (Os serviços de suporte técnico - por telefone ou e-mail - não ajudam, porque não explicam as coisa em termos compreensíveis), 19 (Às vezes, você acha que os sistemas de tecnologia não são projetados para serem usados por pessoas comuns), 20 (Não existe manual de produto ou serviço de alta tecnologia que seja escrito em uma linguagem simples, 26 (Novas tecnologias tornam muito fácil para o governo e as empresas espionar as pessoas), 27 (As tecnologias parecem sempre falhar no pior momento possível).

- Constructo Insegurança: questões 33 (Sempre que algo se torna automatizado, é necessário checar, cuidadosamente, se a máquina ou o computador não está cometendo erros), 35 (Quando você liga para uma empresa, você prefere falar com uma pessoa a uma máquina).

O modelo final está ilustrado na Figura 3, com duas devidas cargas fatoriais. Nesse sentido, chama a atenção que o constructo insegurança o maior coeficiente na relação com a variável uso declarado $(0,259$ em 
módulo), ainda que negativo, o que sugere que quanto maior a insegurança menor o uso. Nesse sentido, esse parece ser o constructo a ser trabalhado em eventuais ações para o crescimento do uso de mobile banking.

Em seguida, aparecem, na ordem, os constructos, inovatividade $(0,230)$, otimismo $(0,213)$ e desconforto $(-0,112)$, esse último negativo, sugerindo uma relação inversa, ou seja, quanto maior a insegurança menor o uso, ou vice-versa.

Registre-se ainda que todas as relações apresentaram estatística t superior à 1,96, sugerindo a existência de todas as relações.

Figura 3 - Modelo Final

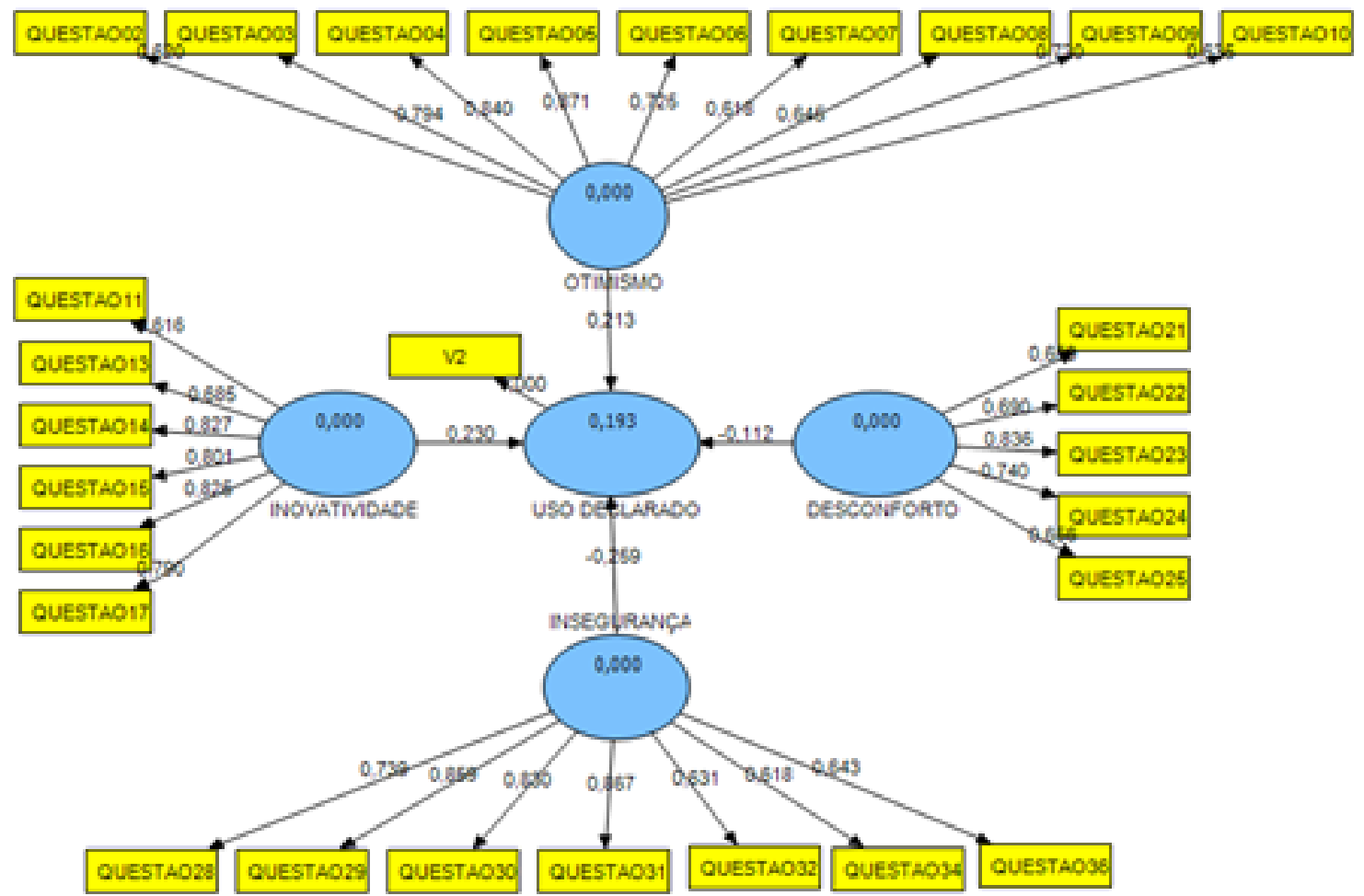

Fonte: Elaborado pelos autores (2017).

Esses resultados vão de encontro com os achados de Pires e Costa Filho (2008) que acharam como único constructo estatisticamente significante o otimismo, com a diferença da variável dependente ser intenção e não uso declarado.

Quanto ao poder de explicação do modelo, registre-se um coeficiente de explicação de 19,3\%, o que segundo Cohen (1998) representa uma explicação média, ou seja, a variação dos quatro constructos explica 19,3\% do uso efetivo de mobile banking na amostra estudada.

Ainda, cabe registrar, os principais indicadores de qualidade de ajuste do modelo. Nesse sentido, a Tabela 2 apresenta os indicadores de validade convergente e confiabilidade do modelo, sugerindo um bom ajuste, de forma geral. 
Tabela 2 - Indicadores de Validade Convergente e Confiabilidade do Modelo

\begin{tabular}{|c|c|c|c|c|}
\hline Indicador & $\begin{array}{l}\text { Critério de } \\
\text { referência }\end{array}$ & Referências & \multicolumn{2}{|c|}{$\begin{array}{l}\text { Valor encontrado no modelo } \\
\text { final }\end{array}$} \\
\hline \multirow{4}{*}{$\begin{array}{l}\text { Variância Média } \\
\text { Extraída (AVE) }\end{array}$} & \multirow{4}{*}{$>0,50$} & \multirow{4}{*}{$\begin{array}{l}\text { Henseler; Ringle e } \\
\text { Sinkovics (2009) }\end{array}$} & Otimismo & 0,53 \\
\hline & & & Inovatividade & 0,58 \\
\hline & & & Desconforto & 0,52 \\
\hline & & & Insegurança & 0,56 \\
\hline \multirow{4}{*}{ Alpha de Cronbach } & \multirow{4}{*}{$>0,70$} & \multirow{4}{*}{ Hair et al. (2014) } & Otimismo & 0,91 \\
\hline & & & Inovatividade & 0,86 \\
\hline & & & Desconforto & 0,84 \\
\hline & & & Insegurança & 0,90 \\
\hline \multirow{4}{*}{$\begin{array}{l}\text { Confiabilidade } \\
\text { Composta }\end{array}$} & \multirow{4}{*}{$>0,70$} & \multirow{4}{*}{ Hair et al. (2014) } & Otimismo & 0,89 \\
\hline & & & Inovatividade & 0,86 \\
\hline & & & Desconforto & 0,77 \\
\hline & & & Insegurança & 0,87 \\
\hline
\end{tabular}

Fonte: Editado pelos autores (2017)

\section{CONCLUSÃO}

Este artigo buscou avaliar o modelo bastante conhecido, o índice de prontidão à tecnologia Technology Readiness Index (TRI), desenvolvido por Parasuraman (2000) e Parasuraman e Colby (2002) e testar os quatro constructos que compõem o TRl, otimismo, inovatividade, desconforto e insegurança, junto aos clientes bancários de instituições financeiras.

Em relação aos 219 questionários validados, deve-se atentar às características dos avaliados, a predominância do sexo feminino de $56,7 \%$ contra $42,5 \%$ homens. A idade média dos entrevistados foi de 35 anos, com mediana de 33 anos e desvio padrão de 12 anos. Em relação ao grau de instrução, predominância o ensino médio completo $51,9 \%$, em seguida $19,9 \%$, com relação à faixa de renda mensal familiar, mais de $60 \%$ da amostra apresenta renda entre $R \$ 880,00$ e $R \$ 3.520$. Destaca-se que $17 \%$ dos entrevistados afirmaram possuir renda familiar de até 1 (um) salário mínimo, com vigência de $R \$ 880,00$ (DIEESE, 2016).

Frente aos serviços bancários, cabe registrar que $45,6 \%$ da amostra pesquisada informou utilizar o mobile banking de seu banco principal para realizar algum tipo de operação ou transação. Por meio da análise quantitativa realizada sobre os dados coletados com o modelo PLS, foi possível verificar que o constructo insegurança com o maior coeficiente na relação com a variável uso declarado.

A segunda maior relação causal é identificada no modelo final é entre constructo inovatividade e uso declarado com o valor de 0,230 sendo que os clientes bancários apontam que o maior desafio é entender o uso de equipamentos de tecnologia, verificável na tabela $1 \mathrm{com}$ média 6,74 e o item com menor média do constructo é a adoção da tecnologia de maneira pioneira com a média de 5,05.

Por sua vez os dois constructos com menor relação causal pelo PLS, foram o desconforto e a insegurança com valores de $-0,112$ e $-0,269$ respectivamente sugerindo uma relação inversa, ou seja, quanto maior a insegurança menor o uso, ou vice-versa, sendo que no caso do desconforto a maior média obtida de uma das questões foi a facilidade hipotética de o governo ou empresas espionarem o cliente, e no caso da insegurança a relação humana para a execução da atividade financeira atingiu a média de 7,63 , todavia para este mesmo constructo a insegurança intrínseca a este tipo de atividade foi constata pela média de 5,74. Registre-se ainda que todas as relações apresentaram estatística t superior à 1,96, sugerindo a existência de todas as relações.

Esse tema ainda deve ser estudado com mais profundidade no âmbito de outros públicos, além disso, é preciso se debruçar mais sobre o tema avançando os estudos, relacionados a estratégias específicas de organizações. 
As evidências estatísticas apuradas no estudo indicam que a intenção de continuar utilizando um produto ou serviço é diretamente influenciada pela utilidade que este representa pelo cliente bancário, assim como pela facilidade com que este produto é operado. As análises estatísticas indicaram, que o fato de que uma predisposição positiva em relação à tecnologia, representada pelo fator otimismo, também tem parcela de influência, ainda que modesta, sobre a intenção de uso continuado. Isto implica que o uso da tecnologia de forma positiva, é creditável pela oferta hipotética de maior controle, flexibilidade e eficiência para os clientes bancários, o que vai ao encontro com os achados de Pires e Costa Filho (2008).

É importante destacar que essa pesquisa possui uma série de limitações como a amostra coletada de clientes bancários de apenas uma agência. A segunda limitação foi o prazo exíguo da coleta de dados. Frente a essas restrições, identifica-se a necessidade de novas pesquisas sobre o tema que tais como a aplicação do TRI a outros ambientes organizacionais.

A sugestão para futuras pesquisas é a replicação deste estudo em outras instituições não necessariamente financeiras, e junto aos clientes bancários que frequentam as agências presencialmente em dias de maior movimento, a fim de investigar a adoção ou não de novas tecnologias como no caso de um canal alternativo mobile banking. Recomenda-se do mesmo modo, a ampliação da amostra e diversificação dos pontos de entrevista, com vista a identificar influências de aspectos culturais que influenciem usuários e clientes bancários a utilizarem as novas tecnologias bancárias.

\section{REFERÊNCIAS}

COHEN, J. Statistical power analysis for the behavioral sciences. 2. ed. New York: Psychology Press, 1998.

DAVIS, F.; BAGOZZI, R.; WARSHAW, P. User acceptance of computer technology: a comparison of two theoretical models. Management Science, v. 35, n. 8, p. 982-1003, 1989.

DIEESE - DEPARTAMENTO INTERSINDICAL DE ESTATÍSTICA E ESTUDOS SOCIOECONÔMICOS. Política de
valorização do salário mínimo. Disponível em
<http://www.dieese.org.br/notatecnica/2015/notaTec153SalarioMinimo2016.pdf> . Acesso em: 06 jul. 2016.

FEBRABAN. Você e seu banco: um guia que vai facilitar seu relacionamento com os bancos, 2015. Disponível em: <http://www.bnb.gov.br/documents/76079/76234/cartilha_febraban_intranet.pdf/e8781613-917c-4fe18da5-3029eec609d1>. Acesso em: 10 jul. 2016.

ENGEL, J. F.; BLACKWELL, R. D.; MINIARD, P. W. Comportamento do consumidor. São Paulo: Cengage Learning, 2011.

HAIR, J. F; HULT, T. M.; RINGLE, C. M.; SARSTEDT, M. A. Primer on partial least squares structural equation modeling (PLS-SEM). Los Angeles: SAGE, 2014.

HENSELER, J.; RINGLE, C. M.; SINKOVICS, R. R. The use of partial least squares path modeling in international marketing. Advances in International Marketing, v. 20, p. 277-319, 2009.

JEUNON, E. Valores e orientação de consumo: proposta e validação de um modelo integrativo. In: ENCONTRO NACIONAL DA ASSOCIAÇÃO NACIONAL DOS PROGRAMAS DE PÓS-GRADUAÇÃO EM ADMINISTRAÇÃO, 29, 2005, Brasília. Anais do Enanpad. Brasília: Anpad, 2005.

KALAKOTA, R.; ROBINSON, M. M-business: tecnologia móvel e estratégia de negócios. Porto Alegre: Bookman, 2002.

MARTINS, G. M. Formação dos contratos eletrônicos de consumo via internet. Rio de Janeiro: Forense, 2003. 
MEUTER, M. L.; OSTROM, A. L.; ROUDTREE, R. I.; BITNER, M. J. Self-service technologies: understanding customer satisfaction with technology-based service encounters. Journal of Marketing, v. 64, n. 3, p. 50-65, jul. 2000.

MICK, D.; FOURNIER, S. Paradoxes of Technology: consumer cognizance, emotions and coping strategies. Journal of Consumer Research, v. 25, n. 20, p. 123-143, 1998.

MIDGLEY, D. F.; DOWLING, G. R. Inovativeness: the concept and its measurement. Journal of Consumer Research, Chicago, v. 4, n. 44, p. 229-242, 1978.

PARASURAMAN, A. Technology Readiness Index (TRI): a multiple-item scale to measure readiness to embrace new technologies. Journal of Service Research, v. 2, n. 4, p. 307-320, mai. 2000.

PARASURAMAN, A.; COLBY, C. L. Marketing para produtos inovadores: como e por que seus clientes adotam tecnologia. Porto Alegre: Bookman, 2002.

PETER, J. P.; OLSON, J. C. Understanding Consumer Behavior. Burr Ridge: Irwin, 1994.

PIRES, P. J.; COSTA FILHO, B. A. Fatores do índice de prontidão à tecnologia (TRI) como elementos diferenciadores entre usuários e não usuários de internet banking e como antecedentes do modelo de aceitação de tecnologia (TAM). Revista de Administração Contemporânea, Curitiba, v. 12, n. 2, p. 429-456, abr./jun. 2008.

PONTAROLO, C. Como uma marca reconhecida como inovadora modera a prontidão à adoção de nova tecnologia do consumidor curitibano de produtos tecnológicos. 2014. 150 f. Dissertação (Mestrado em Administração) - Programa de Pós-Graduação em Administração, Universidade Federal do Paraná, Curitiba, 2014.

POUSTTCHI, K.; SCHURIG, M. Assessment of today's mobile banking applications from the view of customer requirements. In: Annual Procceding of the Hawaii International Conference on System Sciences, jan.5-8, 2004, Big Island, Hawaii. Annals of the $37^{\circ}$ Annual Procceding of the Hawaii International Conference on System Sciences, Big Island, Hawaii, 2004.

PREARO, L. C. Os serviços públicos e o bem-estar subjetivo da população: uma modelagem multigrupos baseada em mínimos quadrados parciais. 2013. 274 f. Tese (Doutorado em Métodos Quantitativos) Programa de Pós-Graduação em Administração, Universidade de São Paulo, São Paulo, 2013.

RINGLE, C. M.; SILVA, D. da; BIDO, D. Modelagem de equações estruturais com utilização do SmartPLS. Revista Brasileira de Marketing (REMark), v. 13, n. 2, p. 56-73, mai. 2014.

RITA, L. P. S.; VIANA FILHO, J. C.; PAULA, M. A. Gadgets Eletrônicos: uma análise da adoção e produtos e serviços inovadores utilizando a Technology Readiness Index (TRI). In: ENCONTRO DA ASSOCIAÇÃO NACIONAL DE PÓS-GRADUAÇÃO E PESQUISA EM ADMINISTRAÇÃO (ENANPAD), set. 6-10, 2008, Rio de Janeiro, RJ. Anais do XXXII Enanpad, Rio de Janeiro, RJ, 2008.

ROBERTSON, T. S. Innovative Behavior and Communication. New York: Holt Rinehart \& Winston, 1971

ROCHA, T. W. P.; BEVILACQUA, S. Prontidão à tecnologia: um estudo sobre a aplicação da Techonogy Readiness Index (TRI) na cidade de Catalão, GO. Revista de Administração da UFSM, v. 4, n. 3, p. 352-363, 2011.

ROGERS, E. M. Diffusion of Innovations. 4. ed. New York: The Free Press, 1995

ROSEN, L. D.; SEARS, D. C.; Weil, M. M. Computerphobia, behaviour research methods. Instruments and Computers, v. 19, n. 2, p.167-179, 1987. 
SAAKSJARVI, M. Consumer adoption of technological innovations. European Journal of Innovation Management, v. 6, n. 2, p. 90-100, 2003.

SOUZA, R. V. Adoção de produtos e serviços baseados em tecnologia pelo consumidor: uma avaliação da aplicabilidade da Technology Readiness Index no contexto brasileiro. 2002, 114 f. Dissertação (Mestrado em Administração) - Programa de Pós-graduação em Administração, Universidade Federal do Rio Grande do Sul, Porto Alegre, 2002.

SOUZA, R. V.; LUCE, F. B. Adoção de produtos e serviços baseados em tecnologia: uma avaliação da aplicabilidade do Technology Readiness Index (TRI) no Brasil. In: ENCONTRO DA ASSOCIAÇÃO DOS PROGRAMAS DE PÓS-GRADUAÇÃO EM ADMINISTRAÇÃO (ENANPAD), 2003, Atibaia. Anais do XXVII ENANPAD, Atibaia, SP, 2003.

SOUZA, R. V.; LUCE, F. B. Avaliação da Aplicabilidade do Technology Readiness Index (TRI) para a Adoção de Produtos e Serviços Baseados em Tecnologia. Revista de Administração Contemporânea, v. 9, n. 3, p. 121141, jul./set. 2005.

TSIKRIKTSIS, N. A technology readiness-based taxonomy of customers: a replication and extension. Journal of Service Research, v. 7, n. 1, p. 42-52, 2004. 